\title{
Repetitive crafting: The shared aesthetic of time in Australian contemporary art
}

\author{
Sera Waters
}

\begin{abstract}
This paper analyses a strain of contemporary art that employs a method of production identified as 'repetitive crafting'. This will be explored through the practices of four contemporary Australian artists, all who use repetition to transform everyday gestures and materials into cumulative artistic manifestations. While their works speak of the physical proximities between art and body, including endurance, intimacy, and complex relationships with labour (even obsessive-compulsiveness) it is, above all, the activation of 'time' as both process and aesthetic that is taken up as most important impetus here. I will argue that 'time' within these repetitively crafted works is integrally transferred from the making to viewing processes through networked cultures, and acts to slow down or make space for understanding corporeal and personal connections with 'time' anew. I argue that by employing and exhibiting the aesthetic of 'time' in the relational sphere, such artworks become part of a larger political project to 'encourage an inter-human intercourse which is different to the "zones of communication" that are forced upon us' (Bourriaud, 1998, p. 161).
\end{abstract}

Throughout this paper I am going to "critically describe"1 a particular mode of production within contemporary art, a mode that aesthetically explores, applies and shares 'time'; I will call this 'repetitive crafting'. Repetitive crafting as an idea can be teased out in numerous directions, but in this paper it is located within contemporary art practice, citing work from four Australian artists; Justine Khamara, Tim Sterling, Ray Harris, and Troy-Anthony Baylis. While the output from these artists differs considerably, they are brought together here as each use repetition and time to transform the 'everyday'. Small gestures that singularly could be described as banal are given renewed valued when extended within the context of contemporary art. When accumulated, the gestures of these artists forge connections and create relational experiences; experiences that in this specific case take up and ask for 'time'.

\footnotetext{
1 I am using this term in accordance with John Rajchman's call for a 'lightness' in theory, which is examined throughout his paper 'The Lightness of Theory' (Kocur \& Leung, 2005, pp. 388-394). As well, this paper is indebted to current theories, especially those of Johanna Drucker, Nicolas Bourriaud, Nikos Papastergiadis, Claire Bishop and Jacques Rancière, that arise from within artistic practices and embrace optimistic playfulness, sharing, and proffer complexly human aspects of art making. As such, cool visions of negative criticality as well as oppositions (rational/irrational, art/craft/design, body/mind, amateur/professional, active/passive for example) are recognised as reductive, given the messy intricacies of art practice which importantly happen within lived experience. Accordingly, it is the artists, through their art and correspondence, who inform my analysis on this specific current of contemporary art.
} 


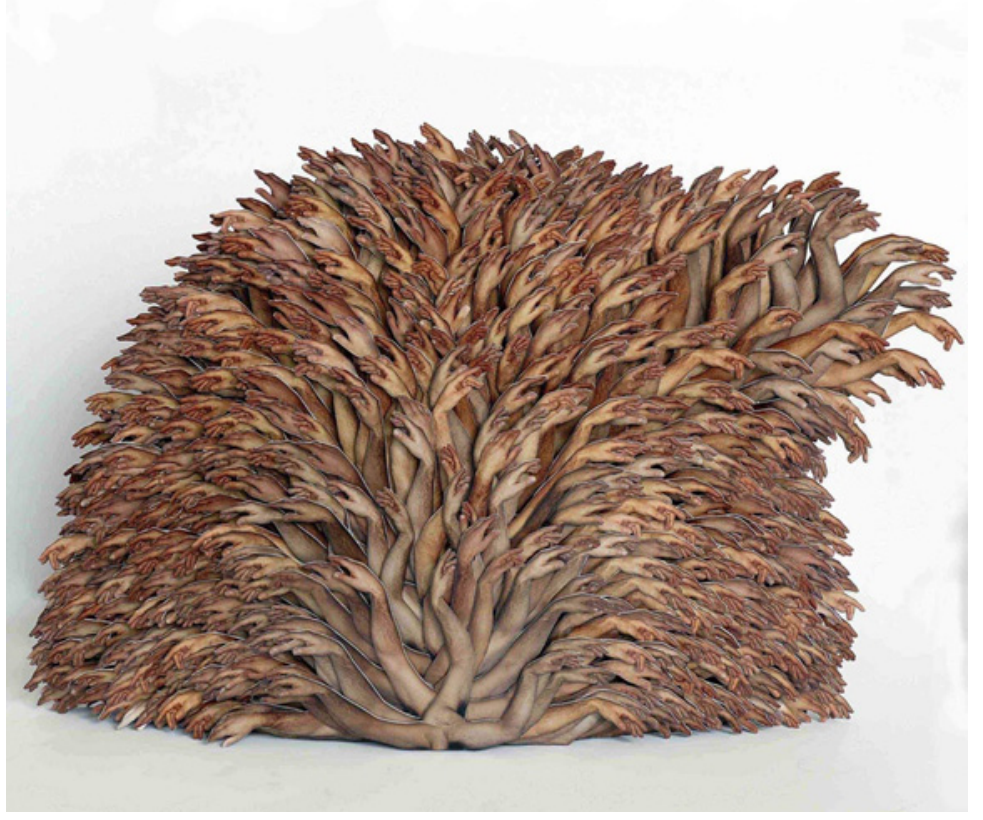

Figure 1. Justine Khamara, godfinger 2, 2007, collaged colour photographs, $43 \times 58 \times 15 \mathrm{~cm}$.

Source: John Brash, courtesy the artist.

Firstly, to clarify what is meant by 'repetitive crafting' Melbourne artist Justine Khamara's godfinger 2 (2007, Figure 1) is used as an exemplar. This is a work collaged into a sculptural form from a mass of scalpel-cut photographs. Repetitiveness as shown here is the re-enactment of a gesture over and over again; cutting one arm, another and yet another again. The monotony of this gesture, with only slight variations in image or blade angle, purposefully devours vast quantities of time. Yet, I argue, located within what could be considered a dreary tedium of repetitiveness is not merely boredom, but 'space' in which alternative relationships to time are forged and presented.

Paired with this idea of repetitiveness is the term 'crafting', a verb stemming from a re-evaluation of the term 'craft', contemporarily understood as 'not a movement or a field, but rather a set of concerns that is implicated across many types of cultural production' (Adamson, 2010, p. 3). While preceded by the historical legacies of 'craft' (guilds and workshops, studio craft, home-craft, hand-craft for example), as well as craft's political entanglements (namely the challenging of gender roles, the DIY (do-it-yourself) craft movement, or an anti-technology/machine sentiment), in these post-medium, postdisciplinary ${ }^{2}$ times, to adapt Ingrid Periz's observation (2008, p. 441), the 'historical freight

2 Though the extent is debatable, 'postdisciplinarity' has dissolved boundaries between the disciplines, such as art craft and design disciplines and allows it to be a given in this paper that particular skills, techniques or processes, which would have once been under the banner of 'craft', cannot today be so simply categorised; an idea supported by Glenn Adamson (2010, p. 586). 
[of craft] is optional'. ${ }^{3}$ Whether or not one is addressing these histories, the use of the term 'craft' and the process of 'crafting' crucially still continue to infer an intimate, skilled and bodily way of making. Within this paper the discussion of artists' 'crafting' encompasses a wide scope of honed and considered gestures that challenge previous values held concerning 'skill' and result in outcomes ranging from film to sculptural objects.

'Repetitive crafting' then can be understood as a dexterous laboriousness, where the relationship between body and material is bound by long periods of concentrated time. The repetitive crafting approach equates the production of art to 'work' and extended 'effort', with making taken to the extreme, even a test of endurance. Melbourne-based artist Tim Sterling's efforts are evident in Pallet (2009, Figures 2 \& 3), or Electric Chair (2010, Figures 4 \& 5), each made from elaborate arrangements of marks, or stationery and fixings. Discussion of 'effort' and 'work' here are not referred to in their economic guises, but hold value in terms of the output of human energy - or even, when I move on to discuss repetitive crafting as relational - as a transference of energy, through its suspension materially within artworks. Repetitive crafting, in this light, is perhaps the marathon of the art world, requiring both physical and psychological stamina, will-power and obsession to reach the finish line (Murakami, 2008).

Like long-distance running, repetitive crafting is often a lone venture, yet its final outcome of sharing is a critical and driving component. For as Nicolas Bourriaud has written, 'artists intend their work to be seen by their contemporaries' (Bourriaud, 1998, p. 167). Troy-Anthoy Baylis' use of repetitive gestures to transform reclaimed glo-mesh in Postcard (To Bella Vista from Cherrybrook), 2010 (Figure 6), is used as a gesture which not only accumulates form, but also meaning in both the making and viewing processes. He writes that while the finished object is more important than the making process ... I am keen for my viewers to 'see the artist's endurance - the artist's commitment to the social and political issues I am talking-back to through the work' (Baylis, 2010). Within the process of repetitive crafting, as Baylis makes clear, is a commitment of one individual's time, alone; a demonstration of the desire (or need) to make and give time in this way. Artistic energy here accumulates as an investment into concerns worth the time - 'time' being the uniting concern of this paper.

3 This adaptation comes from Ingrid Periz's original writing around artists who use embroidery, such as Jessica Rankin, Tracey Emin and Alighiero Boetti, in such as way that it 'takes its place among painting and drawing as just another medium, one whose historical freight is optional' (Periz, 2008, p. 441). 
craft + design enquiry

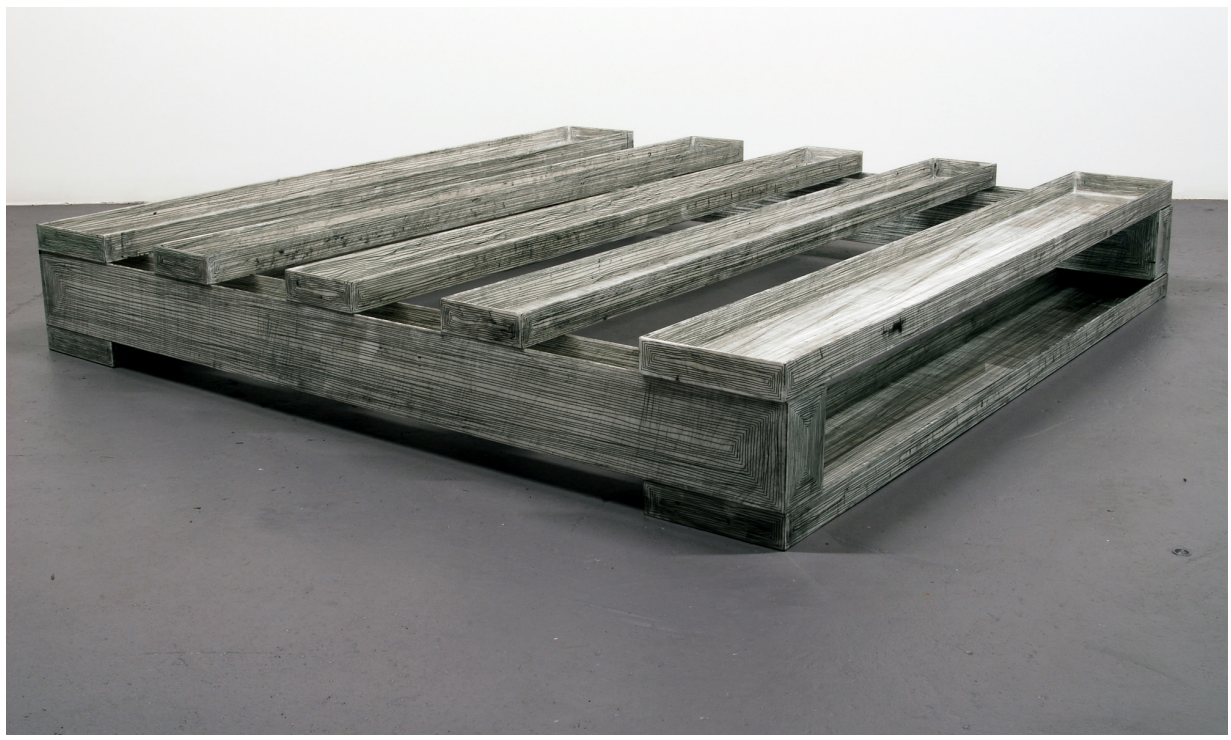

Figure 2. Tim Sterling, pallet, 2009, perspex etched with compass, $117 \times 118 \times 18 \mathrm{~cm}$. Source: Courtesy the artist.

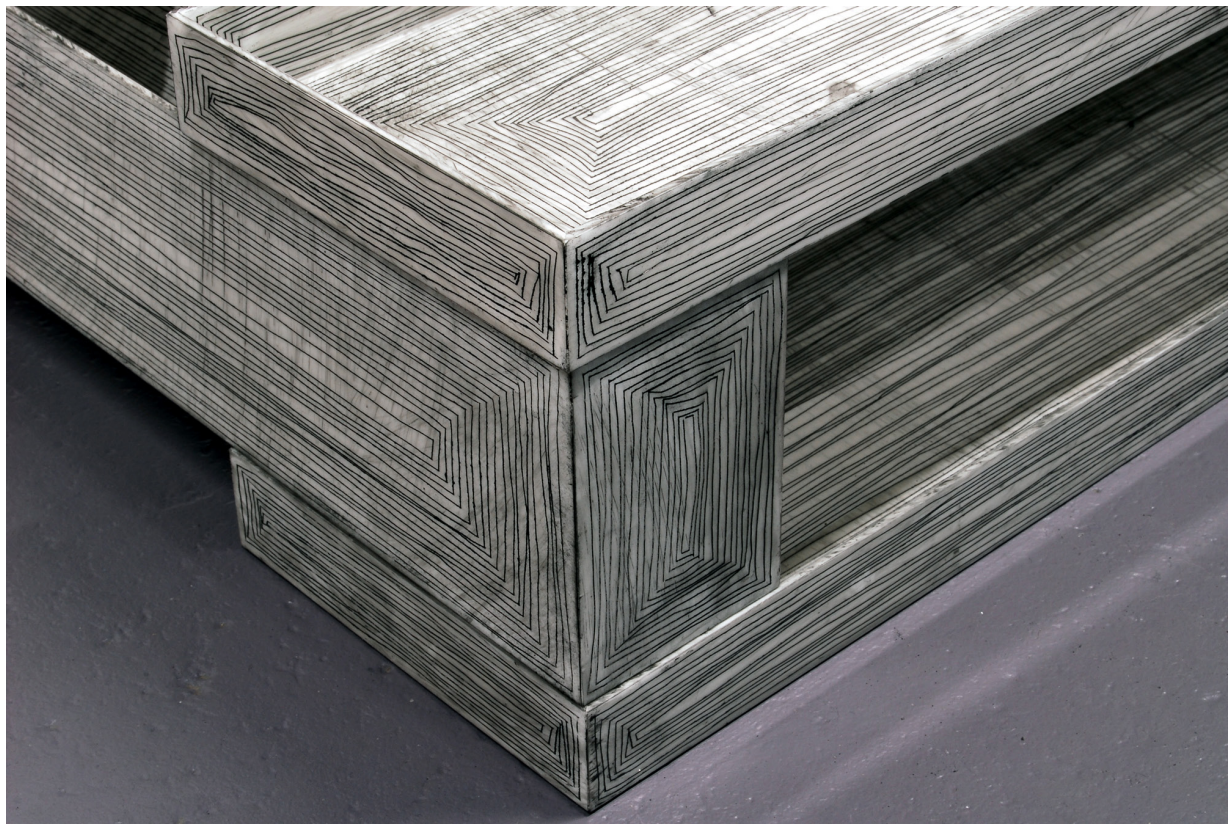

Figure 3. Tim Sterling, pallet (detail), 2009, perspex etched with compass, $117 \times 118 \times 18 \mathrm{~cm}$.

Source: Courtesy the artist. 


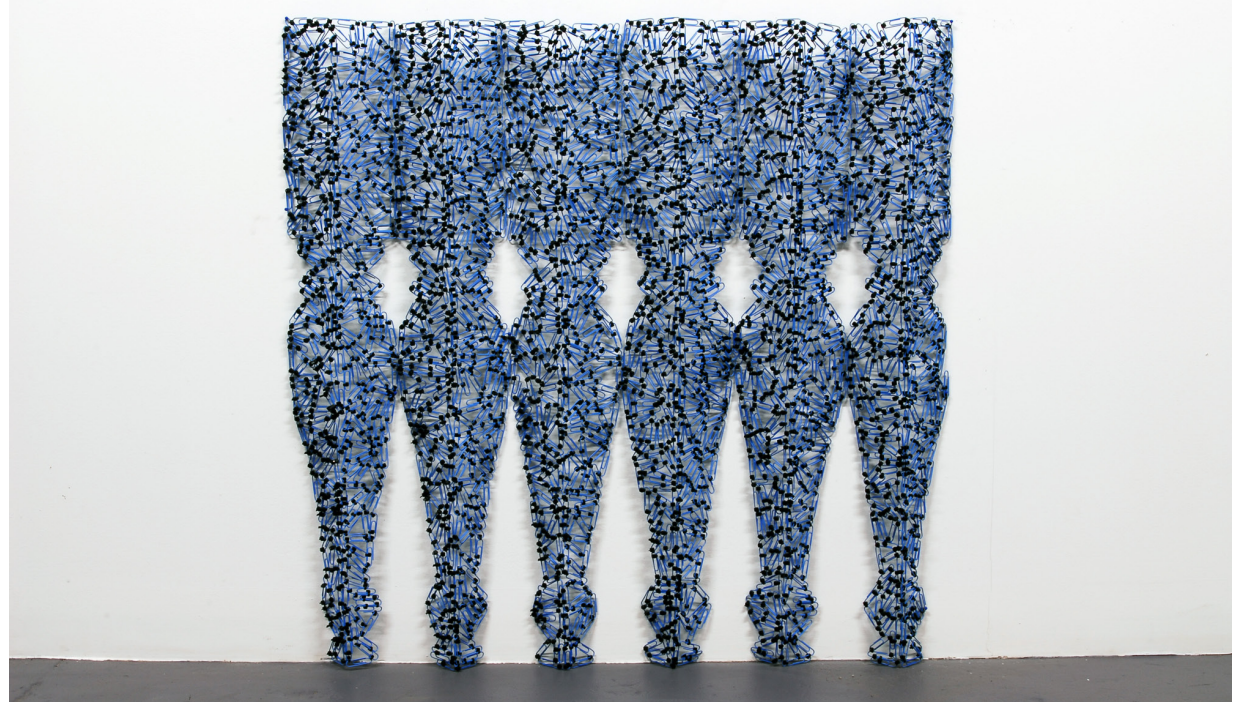

Figure 4. Tim Sterling, electric chair, 2010, paperclips, cable ties, $76 \times 80 \times 4 \mathrm{~cm}$.

Source: Courtesy the artist.

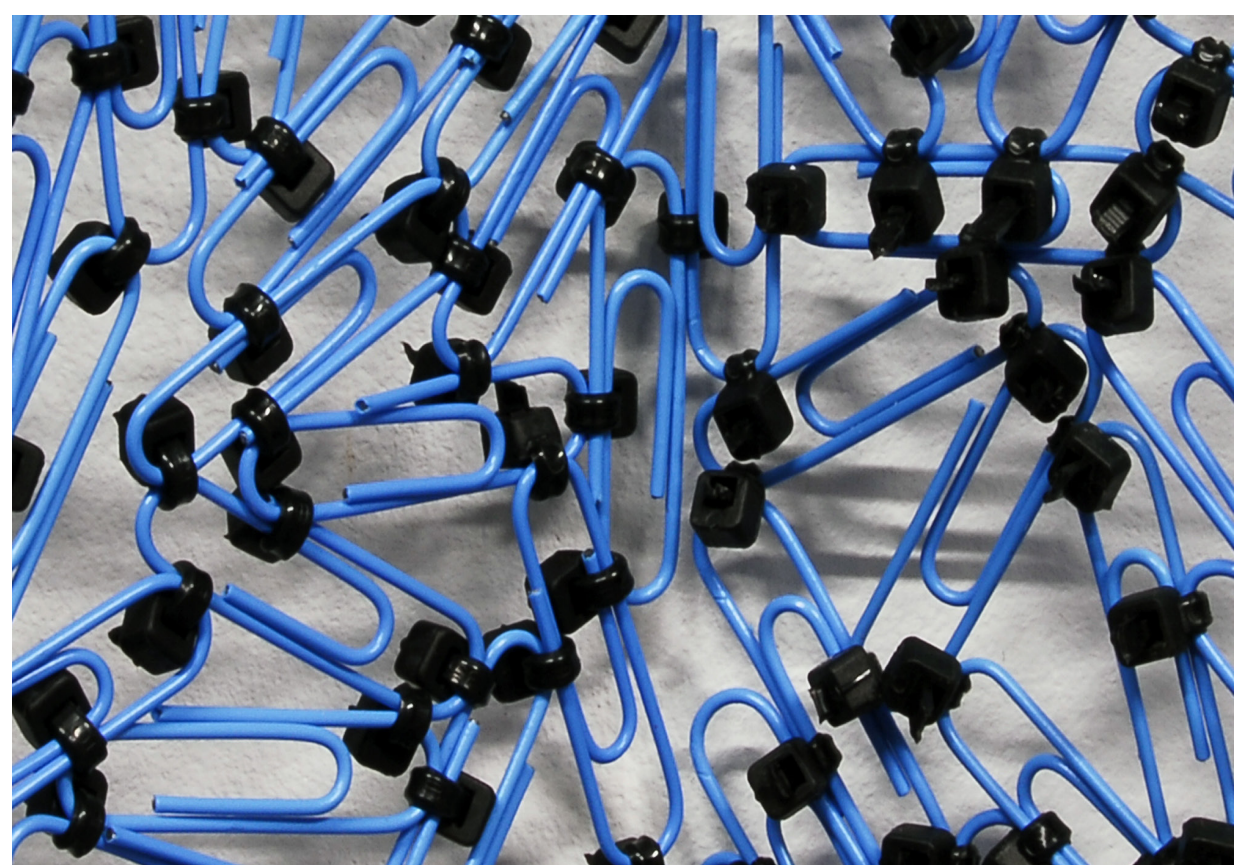

Figure 5. Tim Sterling, electric chair (detail), 2010, paperclips, cable ties, $76 \times 80 \times 4 \mathrm{~cm}$.

Source: Courtesy the artist. 


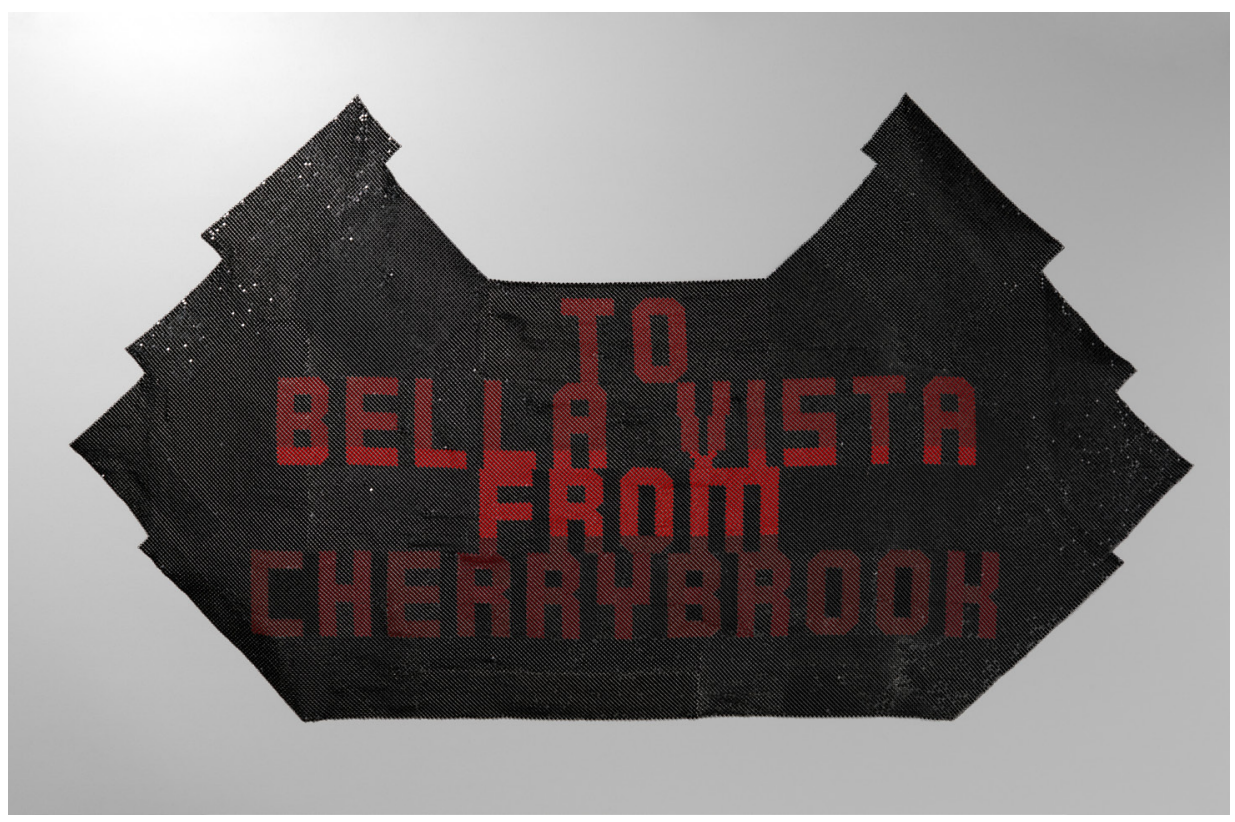

Figure 6. Troy-Anthony Baylis, Postcard (To Bella Vista from Cherrybrook), 2010, reconstructed faux-mesh, approx $90 \times 130 \mathrm{~cm}$.

Source: Troy-Anthony Baylis.

While repetitiveness is integral to many forms of art making - painting or sculpting being obvious examples - repetitively crafted artworks draw attention to the accruement of time. This is their overriding aesthetic, a strand extricated from the larger umbrella term of 'relational aesthetics'. Aesthetics, as Terry Eagleton has described, affect us through 'nothing less than the whole of our sensate life' (Eagleton, cited by Highmore, 2002, p. 81) ${ }^{4}$ and it is phenomenologically then, through our bodily knowledge and human experiences, that time is relayed. Markers of time, such as the hand-cut photographic fragments making up Khamara's Erysichthon's Ball (2010, Figures 7 \& 8), are perceived immediately and in one instant through our own (extensive or limited) encounters with using a scalpel; 5 the grip, the concentration, the hunching over to see, the pressure required, the precision, the slow movement, and the length of time for which one can sustain these taxing gestures. These are also read knowing that programs such as Adobe Photoshop, an integral tool to the early organisational stages of Khamara's work, can capably copy, paste and collage, somewhat reducing the time and physical strain inherent in her undertakings. Laboriousness is Khamara's choice and she says,

4 The quote continues: 'the business of affectations and aversions, of how the world strikes the body on its sensory surfaces, of that which takes root in the gaze and the guts and all that arises from our most banal, biological insertion into the world' (Eagleton, cited by Highmore, 2002, p. 81).

5 Justine Khamara further added 'I was chatting with a couple of plastic surgeons about scalpel technique ... and was surprised to find that the way I approach a work is not unlike the way they might approach a patient'. (Khamara, 2010) 
I ... like the fact that I have touched every piece, traced every outline of the thousands of parts that go into a work and know each anomaly that inevitably appears when one makes something by hand. (Khamara, in Britton, 2007, p. 23)

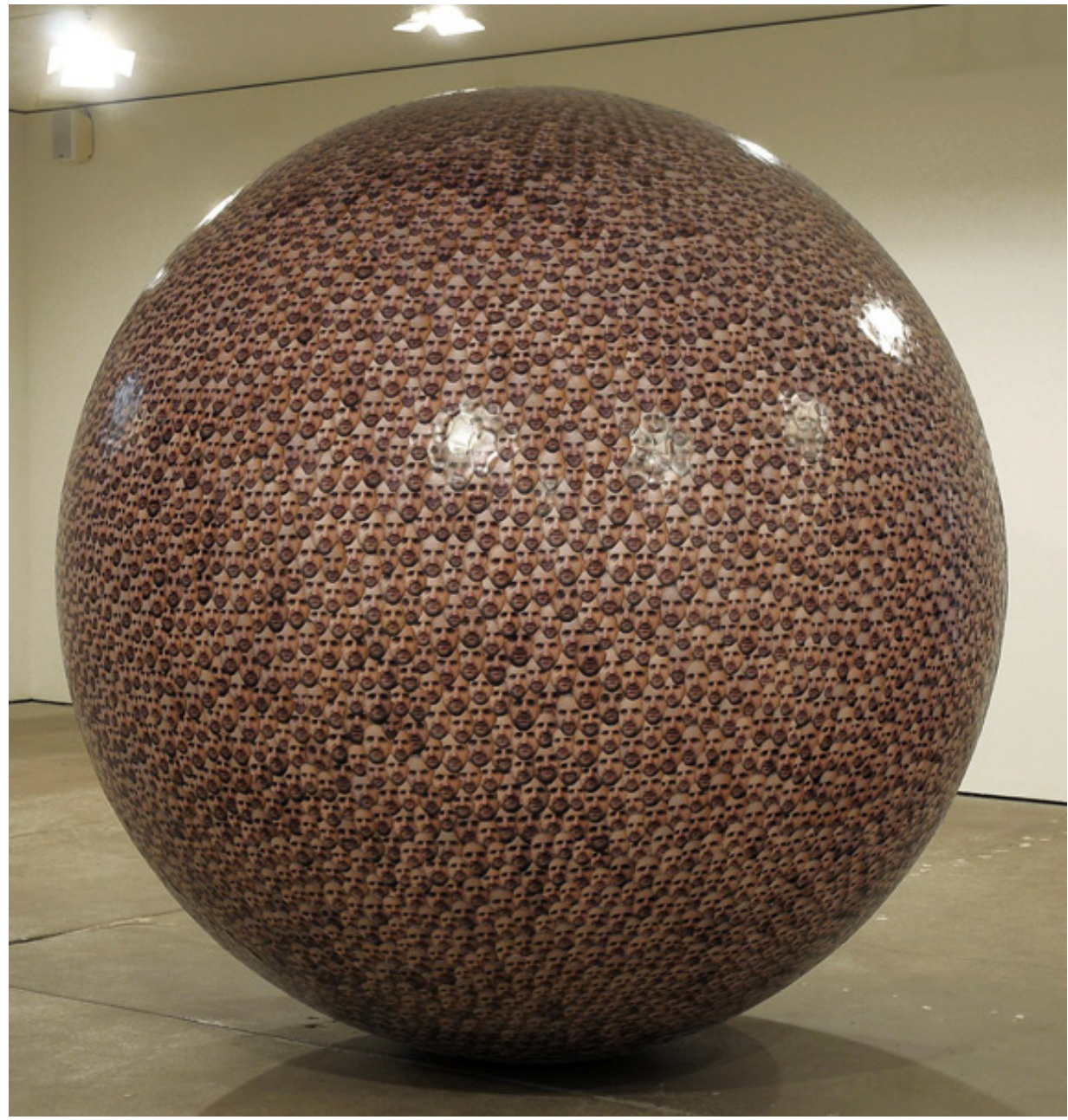

Figure 7. Justine Khamara, Erysichthon's Ball, 2010, $220 \mathrm{~cm}$ diameter.

Souce: John Brash.

This engagement with 'everyday' materials and gestures links the repetitively crafted art discussed here. Each artist plays with and builds upon the unremarkable and commonplace materiality of the everyday as well as a human monotony of habits, routines, work and tasks. When amassed they not only reveal 'the power of relatively simple gestures' (Watkins, 2008, p. 62) but also make evident theorist Henri Lefebvre's observation that the 'everyday' is the site where 'repetition and creativity confront each other' (Lefebvre cited by Johnstone, 2008, p. 15). Importantly, in this way, repetitively crafted works effectively shift from critiquing culture from the outside and instead build connections from within (Papastergiadis, 2008, p. 365). The use of 
small repeated acts explicated with cheap, familiar and non-obtuse materials speak of human interactions with objects in time, such as Tim Sterling's extraordinarily time-involved use of mundane office leftovers in Image (2010, Figures 9 \& 10). Here pencils and cable ties are transformed into complex forms which are materially familiar but configured unfamiliarly. He states:

The general objective of my work is to create sites analogous to ... real life environments by using apparently depersonalised elements that also contain human connotations and connect with life experience. (Sterling, 2010)

Sterling shifts 'stuff' into expressions of human tinkering; playfully and absurdly displacing materials from their intended function. This goes some way to support Ben Highmore's observation that within contemporary art discourse 'much of aesthetics ... is concerned with the everyday only at the point of ... transcendence' (Highmore, 2002, p. 81). However, complete transcendence would be futile here, as it is our continuing recognition of pencils and ties that enables this artwork to remain fathomable and inclusive, connecting through our 'common ground of experience' (Johnstone, 2008, p. 15). Yet embroiled within this argument is the fact that repetitive crafting is reliant upon its reception as an autonomous work of art; even, as I have discussed, when it consists of small gestures with familiar materials that teeter ever so close to 'everyday' life. For in the context of 'contemporary art' such 'everyday' gestures, albeit excessive versions, are transfigured to be critically scrutinized, re-seen, and, at their most effective, offer a 'revelatory experience' (Brook, 2008, p. 273). What is revealed, I argue, are critical analyses and experimentations with 'time', particularly 'real' and complex human relationships with 'time'.

Generally speaking, time and its passing is one of life's major concerns; this line of enquiry leads ultimately to mortality. How we use our life's time, however long that time may be, is a question constantly readdressed through living. 'Time wasted', 'another time', 'out of time', 'family time', 'time-poor', are all descriptors of the way we mark our effective or ineffective management of life's time. 'Management' used in conjunction with time demonstrates the ongoing relevance that 'time is now currency: it is not passed but spent' (Verhagen, 2008), an observation made by British historian EP Thompson half a century ago. Passing the time infers a surplus of time, whereas spending it recognises the pervasive sentiment of time as being fleeting, in short supply and valuable. The recent rise and popularity of the slow movement, which put simply has arisen to address time-poverty ${ }^{6}$ and disconnectedness, attests to this value. It is important here, however, to disentangle repetitive crafting from the slow movement and other forms of resistance or protest that have arisen since industrialisation. Whereas French philosopher Sylviane Agacinski 'argue[s] that one effective resistance to the present order is to waste or give time, to let it pass, to use it unproductively' (cited in Verhagen, 2008), time is spent very productively and consciously within repetitive crafting, working not wasting, but also not partaking in the typical workplace exchange of time and labour for

6 Such values and ethos are portrayed through websites such as: http://www.slowmovement.com/ 
economic reward. ${ }^{7}$ Time working and 'work-life balance', clearly a more grey area than that current aphorism suggests, are the conceptual, investigative domains of repetitive crafting and importantly, the artists who make in this way consciously 'spend' their time in this manner.

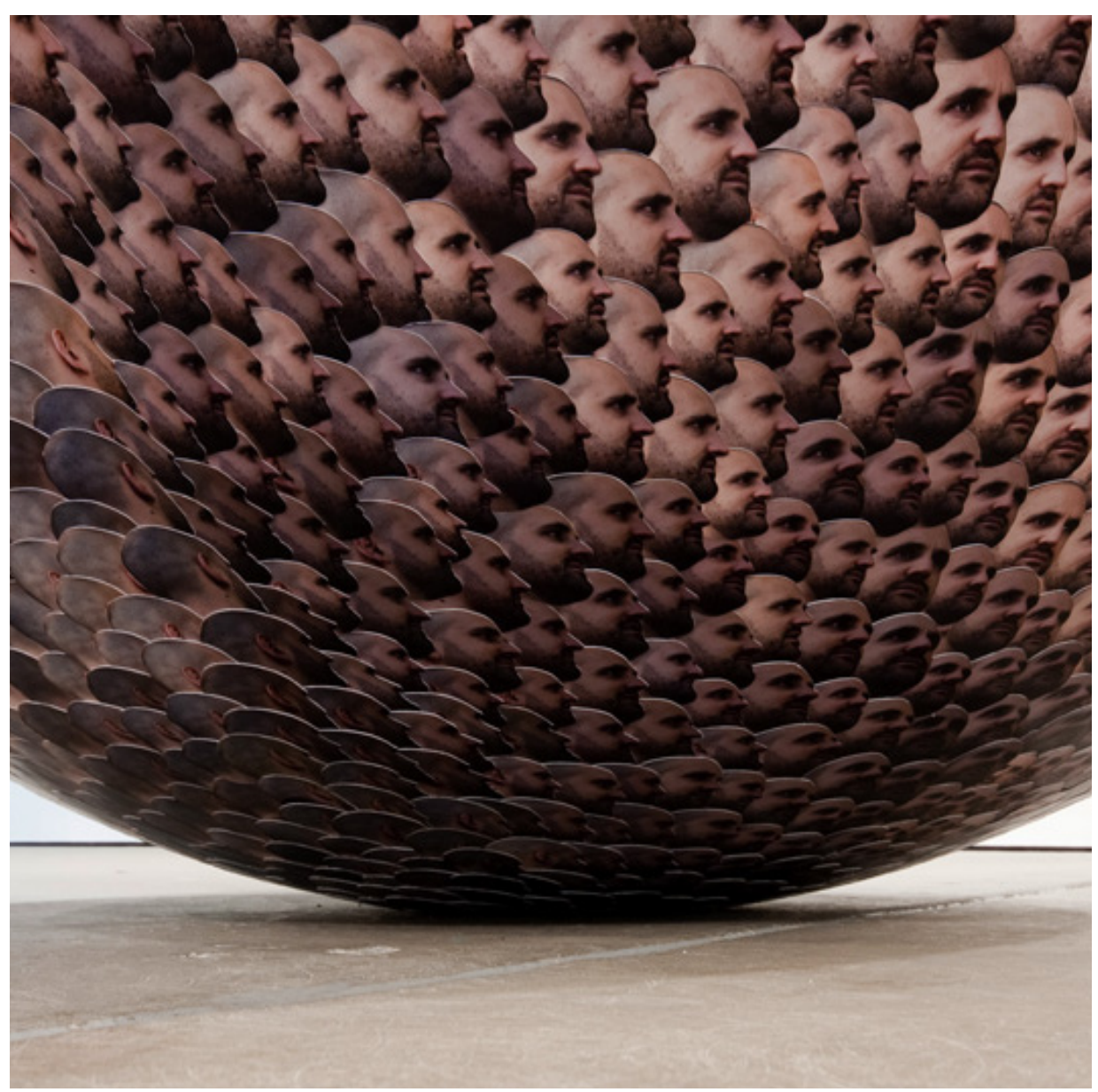

Figure 8. Justine Khamara, Erysichthon's Ball (left side detail), 2010, $220 \mathrm{~cm}$ diameter.

Source: John Brash.

7 It could be added here that repetitive crafting is not concerned with nostalgic anti-technology tenors and is not directly competing with or necessarily making comment on the production values of material culture. Instead repetitive crafting appears strategically made slow to humanise materials through reconfiguration and reorganisation, all the while physically and emotionally engaging with them anew. 


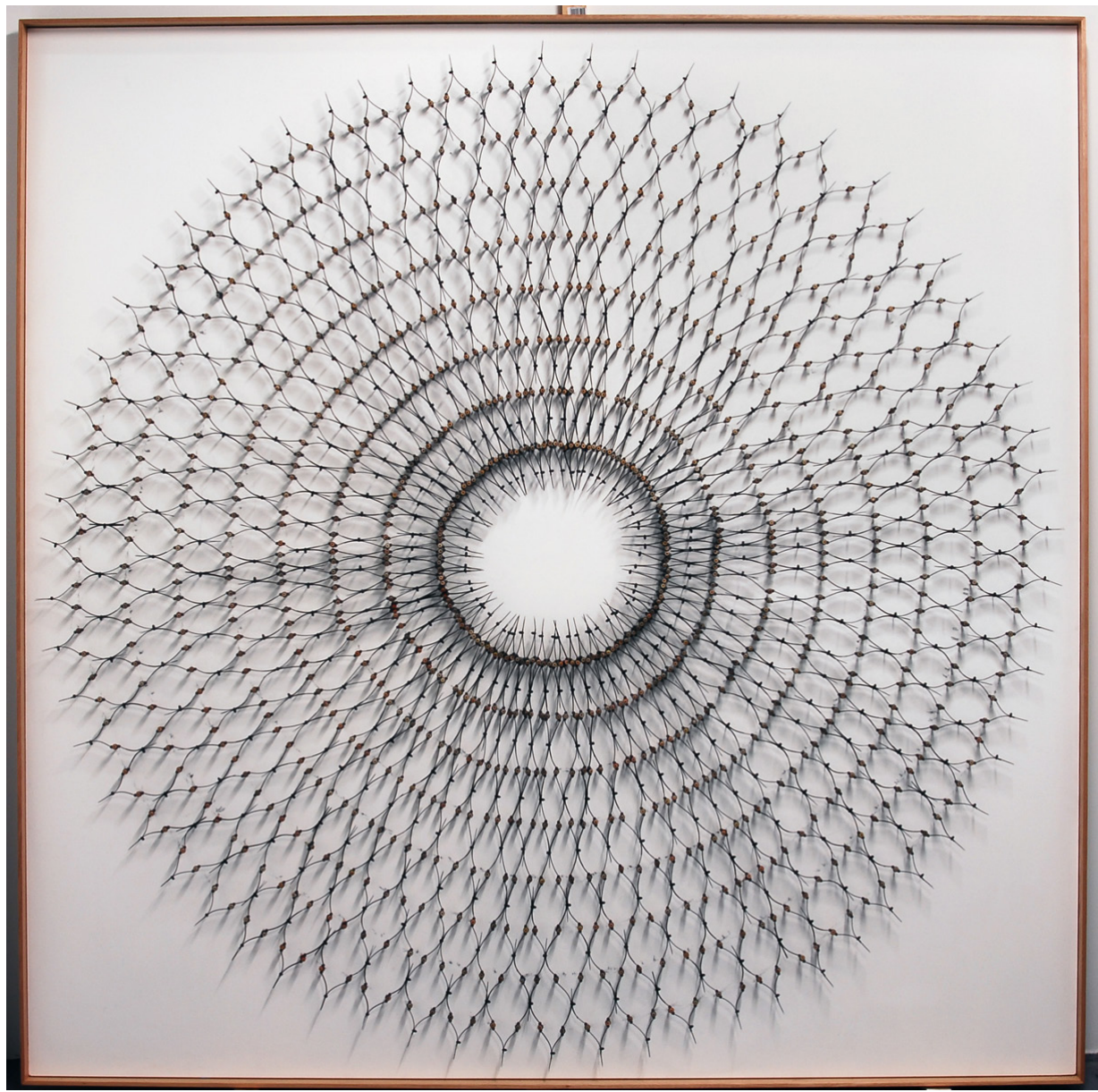

Figure 9. Tim Sterling, image, 2009, pencils, cable ties, $184 \times 184 \times 6 \mathrm{~cm}$.

Source: Courtesy the artist.

Artists who make in slow ways, such as Khamara, recognise a certain risk and absurdity in their art-time investments. ${ }^{8}$ She has remarked:

... as I repeat the same cutting action over and over, trying to do it faster, cleaner, better ... . I develop quite specialised techniques that will probably never be useful in any other context. It feels like a bit of a parody of the tendency today to over-specialise in particular fields of study or work. (Khamara, in Britton, 2007, p. 23)

8 The absurdity of repetitiveness also surrounds theories of the 'everyday' which are described by Ben Highmore as 'precisely what becomes remaindered after rationalist thought has tried to exhaust the world of meaning'; a complex lot of leftovers that as a blurry category are 'inexhaustible, unimpeachable, always open ended and always eluding forms or structures' (Highmore, 2002, p. 80, and Eagleton cited by Highmore, p. 81). 


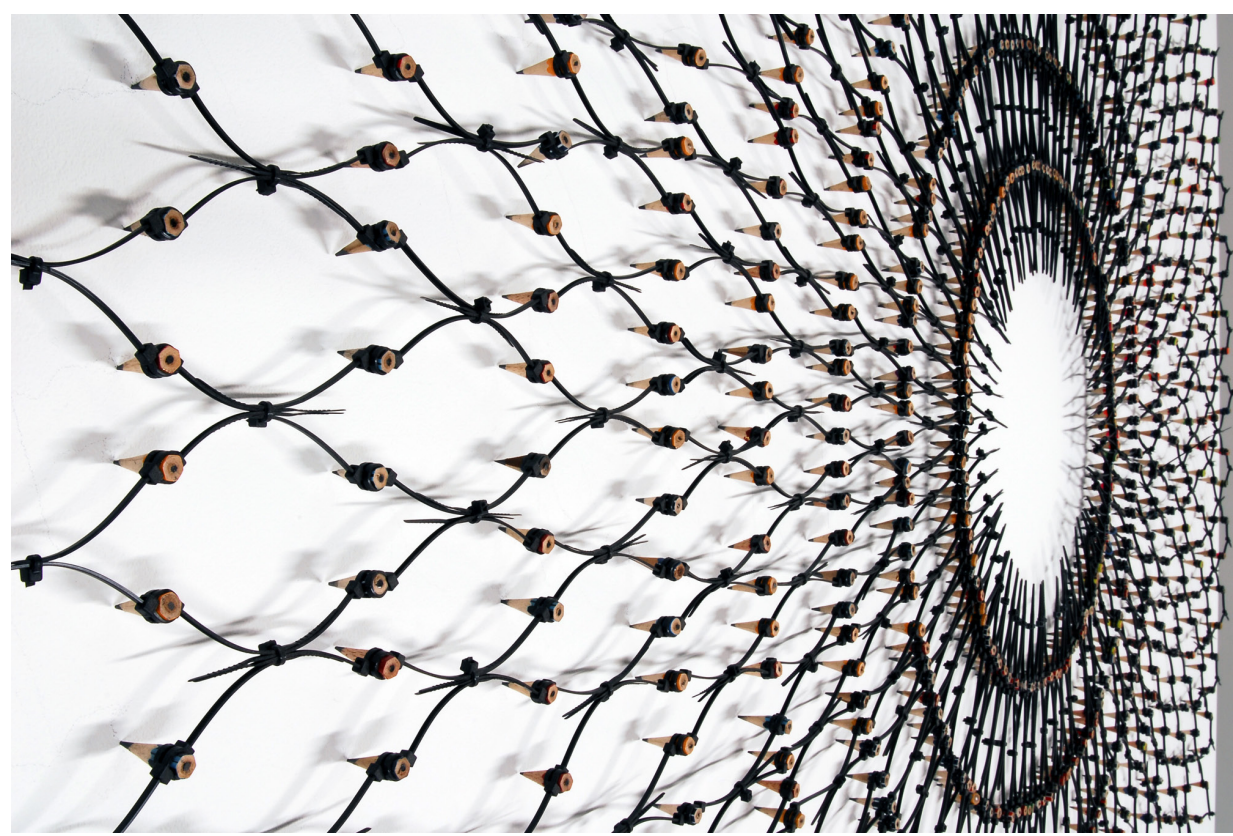

Figure 10. Tim Sterling, image (detail), 2009, pencils, cable ties, 184 x $184 \times 6 \mathrm{~cm}$.

Source: Courtesy the artist.

While recognising her particular skills have been almost honed into obscurity, she playfully points to a similar illogicality in the wider social and economic spheres. A great number of working niches or fields of knowledge are maintained by repetitiveness, and over time have become more and more specialised. In the workplace the absurdity of such specialised repetitiveness is rather invisible, having been largely normalised and rationalised. Paradoxically, repetitive and endurance-based art making - self-driven and often profitless projects - are typically positioned on the irrational side of life (certainly from an economic rationalist stance), as having affinity with madness, or as writer Stephanie Britton teased in an essay written for Artlink, 'obsessive-compulsiveness' (Britton, 2007). Certainly, in the sphere of repetitive crafting being obsessive can be a requirement; Baylis relates that deadlines 'will force me to work extended and uninterrupted hours, days and even weeks to get the work completed in time' (Baylis, 2010). Yet whether obsessive, irrational, stressful, or otherwise, there does remain an irreconcilable tension and inequality of values assigned to these separate work domains, both of which rely upon specialised repetitive actions.

Complicating this further, Alain de Botton, in The Pleasures and Sorrows of Work, describes on a larger philosophical scale the 'average' worker's lament;

our exertions generally find no enduring physical correlatives. We are diluted in gigantic intangible collective projects, which leave us wondering what we did last year and, more profoundly, where we have gone and quite what we have amounted to. (2009, p. 182) 
against the craftsman (or rather craftsperson) who witnesses in their makings:

a stable repository of ... skills and an accurate record of ... years, and hence feel collected together in one place, rather than strung out across projects which long ago evaporated into nothing one could hold or see. (2009, p. 182)

While these observations rely upon simplifications and generalisations, de Botton does make apparent the human desire for work to be transformed, over time, into expressive configurations about human connectivity and one's impact within their world. A sense of control is fundamental to this state, and Khamara (2010) writes:

it feels as though I do what I do as a means of putting things in order, of gaining mastery over a (very) small piece of the world, the only piece I have total control over. And for the thrill of seeing something first seen in my mind's eye made manifest.

While the logic of repetitive crafting can seem strangely absent - for how sustainable (economically, physically and time-wise) are such lengthy undertakings - these artworks suggest important alternatives to the many interactions/transactions of our time.

In contrast to efficient productivity toward a specified outcome, a predominant focus within repetitive crafting is the envelopment in the time-consuming process of making. Nicolas Bourriaud, in his postulating upon contemporary artists and relational aesthetics observed: 'they use time as a raw material ... the production of gestures is more important than the production of material things' (Bourriaud, 1998 , p. 170). While this is apt in relation to repetitive crafting, given it is the time-consuming gesture that speaks foremost, it pays to be reminded again that the final material outcome, the resulting artwork to be shared via exhibition, certainly remains a desirous, vital driving force. Yet there are importantly, the artists convey, benefits to making and taking time to repetitively craft. Baylis says of his lengthy processes which include knitting, 'it allows me to dream to wander - and to focus and concentrate and reflect on what I am doing and the meaning/s of the work' (2010). Khamara, too, appreciates that slow making buys her time to 'slow things down a little; that the time I have embedded in these objects might have its own gravitational pull that tugs one into a more contemplative space for a bit' (2010). Time repeating, then, can create other spaces for the mind to 'work' while the hands continue on into habit. Taking this space analogy further and into a physical territory, Papastergiadis has taken up the artist studio for analysis. He writes that the studio, often located in the abandoned zones of cities, offers:

' ... a location for contemplation and reflection. I imagine that these spaces prompted other unconscious connections, enabled artists to think through the unthought thoughts of our time. These were breathing spaces in which attention was allowed to wander'. (Papastergiadis, 2008, p. 369) 
The run-down, non-demarcated studio, then, is analogous to allocating and investing oneself into pockets of time in order to incessantly repeat, forming 'breathing space' which proffers other interactions with work, time and our world. These disruptions of the usual flow of time Bourriaud terms as 'social interstice', in that they:

... create free spaces and periods of time whose rhythms are not the same as those that organize everyday life, and they encourage an inter-human intercourse which is different to the 'zones of communication' that are forced upon us. (Bourriaud, 1998, p. 161)

The slow time, the down time, and the head space are all avenues with which to disrupt typical flows and exchanges of time.

Likewise, according to Terry Smith, a tendency within contemporary art is 'the taking up of a viewer's time before the work provides enough information about itself for its point to become apparent' (Smith, 2009, p. 194). This requesting or arresting of a viewer's time is evident in all of the works shown thus far each requires the noticing of time spent transforming the ordinary for their effectiveness - but is particularly apt to discussion of Ray Harris's films, looped to be watched time and time again. Slap Happy (2009, Figure 11) and I'm Gonna Wash that Man Right Outta my Hair (2010, Figure 12) take time (several minutes) for the use of repetitive actions to become clear; the subject slapping her face with striking pink paint or increasingly more manically shampooing her hair. Harris suggests that 'repetitiveness in these videos is extremely important as it shows the endurance and intensity of the task which can be painful, dangerous, uncomfortable and confronting' (Harris, 2010). The act of excessive shampooing in Gonna Wash that Man Right Outta my Hair extends a typical cleansing routine into a creative act, transforming the repetitive gesture into one of defiance, catharsis, and offers space for readings alternative to merely shampooing. It is through this repeating of carefully executed but familiar gestures, building over time into a crescendo, that Harris's physical actions read also as states of psychological repetition. She likens this process to 'recreating ... certain situations in your life in the hopes of resolving them, and the unawareness people maintain to their repetitive behaviours (such as "oh I just don't know why I always end up with the bad boy everytime ... ")' (Harris, 2010). In her films Harris's actions are neither sped up nor slowed down but are, importantly, constructed and exhibited through real-time, the experience of time with which we are most familiar. This, alongside their intentional crafting with lofi technology makes Harris's films able to be related to, meaning they both ask for and give back time to contemplate such gestures and head-spaces anew. 


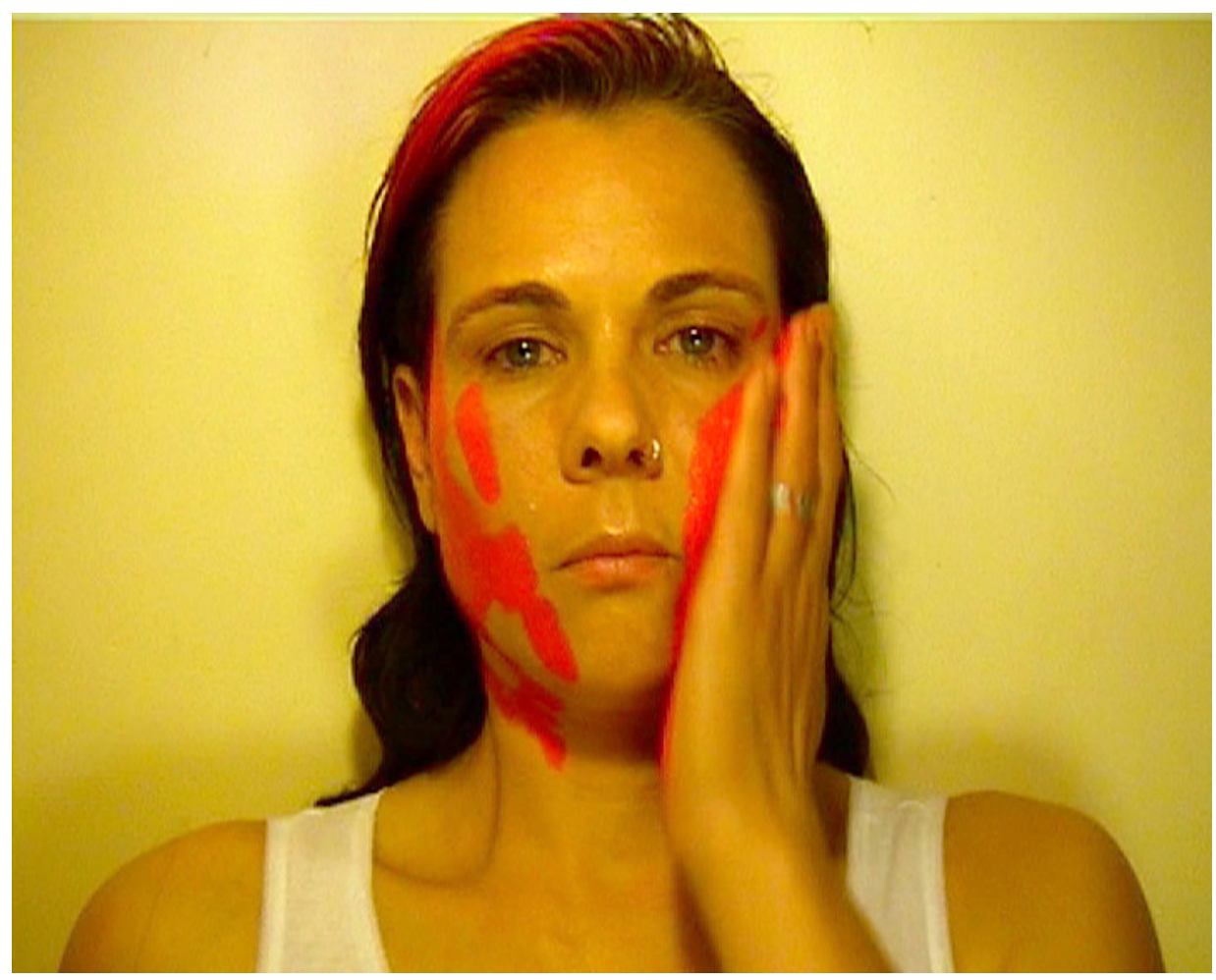

Figure 11. Ray Harris, Slap Happy, 2009, film still from digital video, length 1:49 minutes.

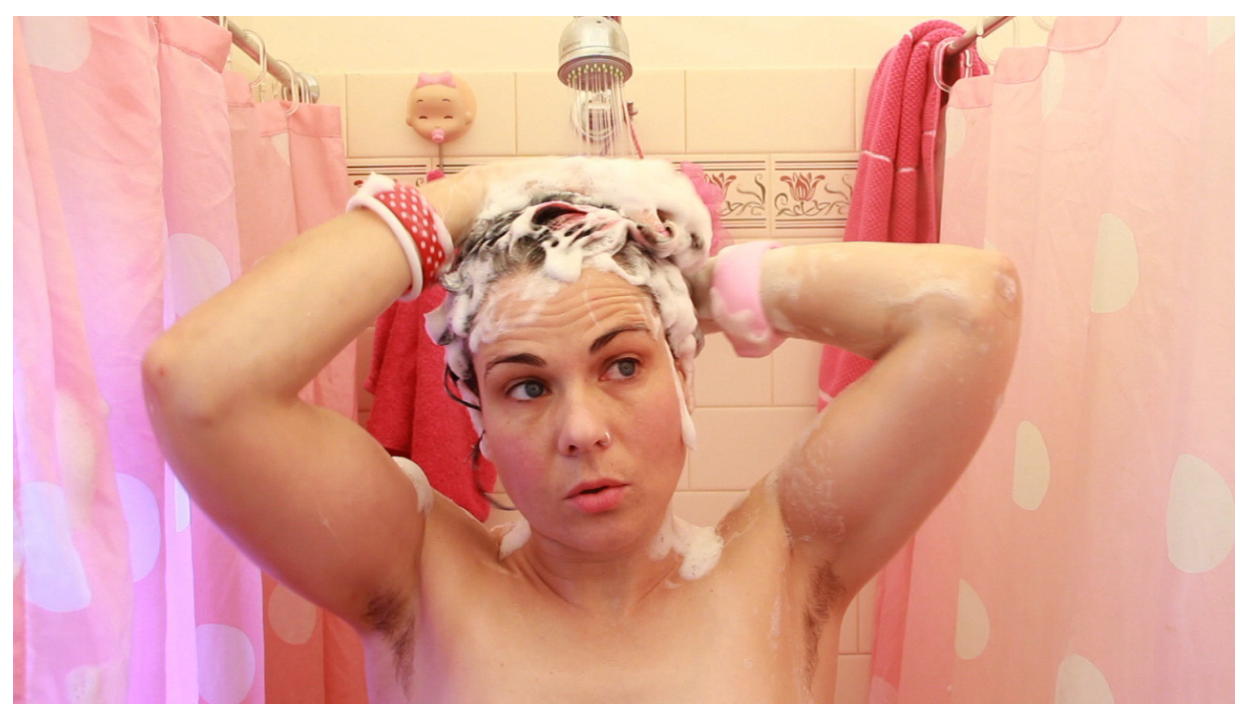

Figure 12. Ray Harris, I'm Gonna Wash that Man Right Outta my Hair, 2010, film still from digital video, length 6:09 minutes. 
Globalism and the condition of 'contemporaneity', or as Terry Smith describes our 'immersion in a plethora of temporalities' (Smith, 2009, p. 198), has simultaneously collapsed and complicated time beyond the human imagination. 'Time-space compression', a term coined by David Harvey in 1989 to speak to the then new modes of communication, consumption, and transport, as well as increased access to information, past, present and future, via network culture, has raised awareness of the infinite cultural and individual perceptions of 'time' (Verhagen, 2008). Troy-Anthony Baylis merges personal, physical, conceptual and historical time critically within his practice. He writes:

Time is a consideration in all my work ... The materialities of many of my objects capture a real-time through the performance of making. The process is definitely time consuming ... Time is also important to me as subject matter as I attempt to articulate personhood through new artefacts that speak to past, sometimes ancient, cultural artefacts and of my people. (Baylis, 2010)

Baylis's art, his works of reclaimed Glomesh as well as his knitted and painted works, all similarly constructed from the repetitive ' $x$ ', reside within multiple temporalities including that of his Indigeneity. The ' $x$ ' playfully transcends singular reading, being diversely posited as standing in for 'l', signifying a kiss, marking the spot, and is a mark present across Baylis's multiple media (Carsley, 2009). Significantly Baylis's work traverses time, space and place, seeking connectivity with the past from the present.

The desire for connectedness within repetitive crafting, I argue, arises from within the reevaluation of 'skill' which has grown from the DIY and all-pervasive rise of craft culture-wide. From repetitive crafting and lengthy and intimate art engagements we can postulate the development of knowledgeable and skilful understandings of material possibilities and limitations. However Glenn Adamson, a prolific writer on contemporary craft, is critical of the postdisciplinary flow of craft techniques, into art and design for example, and has written on the rise of 'sloppy craft' (Adamson, 2010, p. 586). He has made the comment that 'contemporary art spaces have ... approached the subject of postdisciplinary craft, though usually emphasising issues of labour and obsession rather than skill' (Adamson, 2010, p. 587). It must be noted here that though I, too, emphasise endurance, obsession and laboriousness, it is not due to the absence of skill. Conversely, skill, if we extricate it from traditional values, is rapidly proliferating. The so-called 'deskilling of the practice of art' (Burn, 1984, p. 11) from the 1960s has been met by artists with a proactive and inventive, often self-determined self-skilling or re-skilling. In many cases this skilling has been enabled by network cultures; from instructional YouTube videos, online and local communities, shared resources, and the DIY, (or as I prefer the DIT, do-it-together) movement. Through these networks 'skills' have proliferated and flourished, transformed and adapted, and demand to be assessed according to contemporary concerns. 
I argue that terms associated with 'crafting', such as 'skill', 'process' and 'technique', as well as 'craft' itself, have been problematically, even reductively, gauged and quantified within the context of contemporary art. 'Technique', as pointed out by Richard Sennett in his recent text The Craftsman (2008), has often been misperceived as cold, soulless or mechanical (p. 149), yet he explains that such a process 'develops ... by a dialectic between the correct way to do something and the willingness to experiment through error' (2008, p. 160). In this way techniques, skills and crafting can be seen as organic forms of human expression, adapted through trial and error, and suited to growth and change through all varieties of networks and the relational sphere. Judgments of quality and value, which may once have arisen from exactitude or technical perfectionism (the 'correct way'), have been re-emphasised toward dissemination, which today is as highly, perhaps more highly, valued. Certainly the success of blogs such as 'Meet me at Mike's'9 and other networked DIY organisations is located around their encouraging, sharing and of 'giving it a go', and even their celebration of 'amateurism', ${ }^{10}$ including all 'anomalies'.

Skill too, as summarised here by Khamara, need not be materially based:

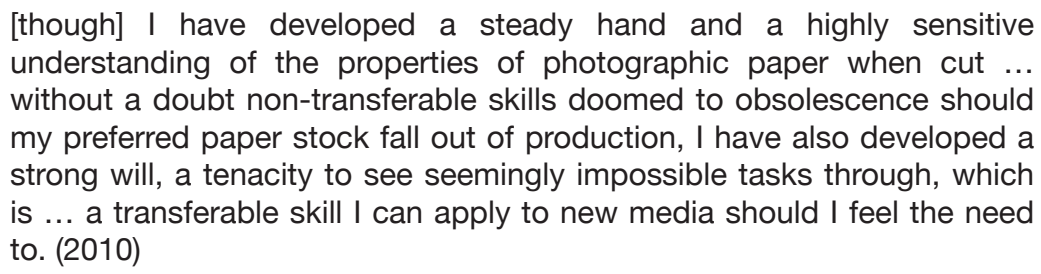

In repetitively crafted artworks such skills as willpower, endurance, striving for the impossible and transferring the commonplace into the extreme, are shared to suggest possibilities for their renewed application and understanding elsewhere. Skill is thus no longer limited to technical proficiency, but has the possibility of being non-material, organic, transferable and relational.

'Relational' though is disputable here, as Bourriaud, the champion of 'relational aesthetics', describes it as art that functions within 'the sphere of human relationships'(Bourriaud, 1998, p. 165), activating participants and even being determined by their interactions. Repetitive crafting, with some exception, generally takes place externally to the 'relational sphere', in the private studio or home, and it is neither interactive nor asks for participation in the making process. Yet I argue that it is relational in several ways. When exhibited, the human connection is experienced through dissemination; via exhibition in galleries, media, websites, blogs, journals and across networked culture. The exhibited artworks enter into the relational sphere as unexpected encounters with ordinary materials and gestures, a variation on Bourriaud's 'day-to-day micro-utopias' (Bourriaud, 1998, p. 163), prompting open-ended and atypical conversations, and furthering possibilities. The artworks also, as evidence of

9 Pip Lincolne, http://meetmeatmikes.blogspot.com/

10 An idea explored in-depth by Glenn Adamson, (thinking through craft, 2007, pp. 139-158). 
human energy used to see through these extraordinary feats, beckon response. One current response encouraged across networks and through DIY ethos is the transference and adaptation of skills, which due to their 'everyday' nature are readily communicable for uptake. And though that response may not be an immediate physical activity taking place within the gallery space, in line with Claire Bishop and Jacques Rancière's critique of Bourriaud's 'relational aesthetics', I propose that the passivity and incapacity often attributed to spectatorship is to be challenged. For, as Rancière writes "looking is also an action ... and ... "interpreting the world" is already a means of transforming it, or reconfiguring it' (Rancière, 2007). Looking and thinking is relational, transformative and powerful. Giving equality to each side of these 'allegories of inequality' will no longer, as Bishop says,

divide audiences into active and passive, capable and incapable, but instead ... invite us all to appropriate works for ourselves and make use of these in ways that their authors might never have dreamed possible. (Bishop, 2006, p. 16)

To conclude, what is the relevance of critically considering repetitive crafting today? If we consider Bishop's observations that 'th[e] DIY, microtopian ethos is what Bourriaud perceives to be the core political significance of relational aesthetics' (2004, p. 54) and insert critically active spectatorship into the equation, it becomes evident that artists who repetitively craft suggest through their amassed small gestures ways to see our everyday interactions with time anew. Within contemporary art practice it is these 'small' performative gestures that arise from within everyday life and have connective power. Johanna Drucker who describes this power: 'art gestures slide the habits of thought into a condition of surprise to disturb the epistemological conventions' (2010, p. 591). In repetitively crafted artworks, playful and obsessive gestures, which are simultaneously investigations into contemporaneity and time, aesthetically connect maker with viewer. Typical daily interactions and expectations of time, work and everydayness are thus disrupted momentarily. Whether viewing these repetitive crafted works directly or reproduced through networked culture, it is within that contemplative space that time, as a complex tangle of human connections, is given, and rewardingly shares.

Sera Waters is an Adelaide-based artist and arts writer. She lectures in Art History and Theory at Adelaide Central School of Art, and teaches in the Postgraduate Art History department, University of Adelaide.

\section{Bibliography}

Adamson, Glenn (ed.), 2010, 'Contemporary Approaches', The Craft Reader, Oxford: Berg, pp. 585-587

Adamson, Glenn, 2007, thinking through craft, Oxford: Berg 
Adamson, Glenn, 2007, 'The Spectacle of the Everyday'. In: Laurie Britton Newell, Out of the Ordinary: Spectacular Craft, Victoria and Albert Museum, London: V \& A Publications, pp. 13-27

Aedy, Richard, 2010, 'The Time Poor Myth', interview with Bob Goodin, Radio National, ABC, 7 July 2010, accessed 25 September 2010, <http://www. abc.net.au/rn/lifematters/stories/2010/2946213.htm>

Bishop, Claire (ed.), 2006, Participation, Documents of Contemporary Art series, London: The MIT Press

Bishop, Claire, 2004, 'Antagonism and Relational Aesthetics', October 110, Fall 2004, pp. 51-79

Bourriaud, Nicolas, 1998, 'Relational Aesthetics' (1998), republished in Participation, Claire Bishop (ed.), London: MIT Press, 2006, pp. 160-171

Bourriaud, Nicolas, 2010, 'Precarious Constructions. Answer to Jacques Rancière on Art and Politics', accessed October 2010, <http://www.skor.nl/ article-4416-nl.html?lang=en>

Britton, Stephanie, 2007, 'The Obsessive compulsive worker-artist', Artlink, Vol. 27 , No 4, pp. 18-24

Brook, Donald,2008, '1968 and all that: 40 Years Later', Broadsheet, Vol. 37, No. 4, pp. 271-273

Carsley, Gary, 2009, 'a rock and a hard place', Troy-Anthony Baylis: Kiss the dirt catalogue

de Botton, Alain, 2009, The Pleasures and Sorrows of Work, New York: Pantheon Books

Drucker, Johanna, 2010, 'Affectivity and Entropy: Production Aesthetics in Contemporary Sculpture', reproduced in Glenn Adamson (ed.), The Craft Reader, Oxford: Berg, pp. 588-595

Highmore, Ben, 2002, 'Everyday Life and Cultural Theory' (2002), reproduced in Stephen Johnstone (ed.), The Everyday, Documents of Contemporary Art series, London: The MIT Press, 2008, pp. 79-87

Johnstone, Stephen (ed.), 2008, 'Introduction: Recent Art and the Everyday', The Everyday, Documents of Contemporary Art series, London: The MIT Press, pp. 12-23

Khamara, Justine, email correspondence, October 2010

Krauss, Rosalind, 2001, 'Mechanical Ballets: light, motion and theatre'. In: Passages in Modern Sculpture, Cambridge, Massachusetts: MIT Press, pp. 201-243 
Miller, Carrie, 2008, 'The Art of Biro', The Art Life, 14 October 2008, <http:// artlife.blogspot.com/2008/10/art-of-biro.html>, accessed 30 September 2010

Murakami, Haruki, 2008, What I talk about when I talk about running: A memoir, New York: Vintage Press

Neil, Jonathan T.D., 'The Aesthetics of Effort', accessed October 2010, <http:// jonathantdneil.com/pdfs/AestheticsOfEffort.pdf>

Paperstergiadis, Nikos, 2008, 'Spatial Aesthetics: Rethinking the Contemporary', in Terry Smith, Okwui Enwezor and Nancy Condee (eds), Antinomies of Art and Culture: Modernity, Postmodernity, Contemporaneity, Durham and London: Duke University Press, pp. 363-381

Periz, Ingrid, 2008, 'Jessica Rankin: The embroidered world', Art \& Australia, Vol. 45, No. 3, pp. 434-441

Rajchman, John, 2005, 'The Lightness of Theory', in Theory in Contemporary Art Since 1985, Zoya Kocur and Simon Leung (eds), Oxford: Blackwell Publishing, pp. 388-394

Radok, Stephanie, 2001, 'A Woman's Touch', in Home is Where the Heart Is, catalogue essay (curator: Vivonne Thwaites), pp. 12-15

Rancière, Jacques, 2007, 'The Emancipated Spectator', ArtForum, March 2007

Roche, Jennifer, 'Socially Engaged Art, Critics and Discontents: An Interview with Claire Bishop', Community Arts Network, Reading Room, accessed October 2010, <http://www.communityarts.net/readingroom/archivefiles/2006/07/ socially_engage.php>

Sennett, Richard, 2008, The Craftsman, London: Penguin Books

Smith, Terry, 2009, What is Contemporary Art?, Chicago: Chicago Press

Verhagen, Marcus, 2008, 'Slow Time', Art Monthly (UK), accessed October 2010, <http://www.artmonthly.co.uk/magazine/site/article/slow-time-bymarcus-verhagen-2008/>

Watkins, Jonathan, 2008, 'Art and the Everyday', reproduced in Stephen Johnstone (ed), The Everyday, Documents of Contemporary Art series, London: The MIT Press, pp. 61-68 